\title{
Genetic and Functional Identifying of Novel Autosomal Dominant STAT1 Loss-of-function Mutations in Patients with Diverse Clinical Phenotypes
}

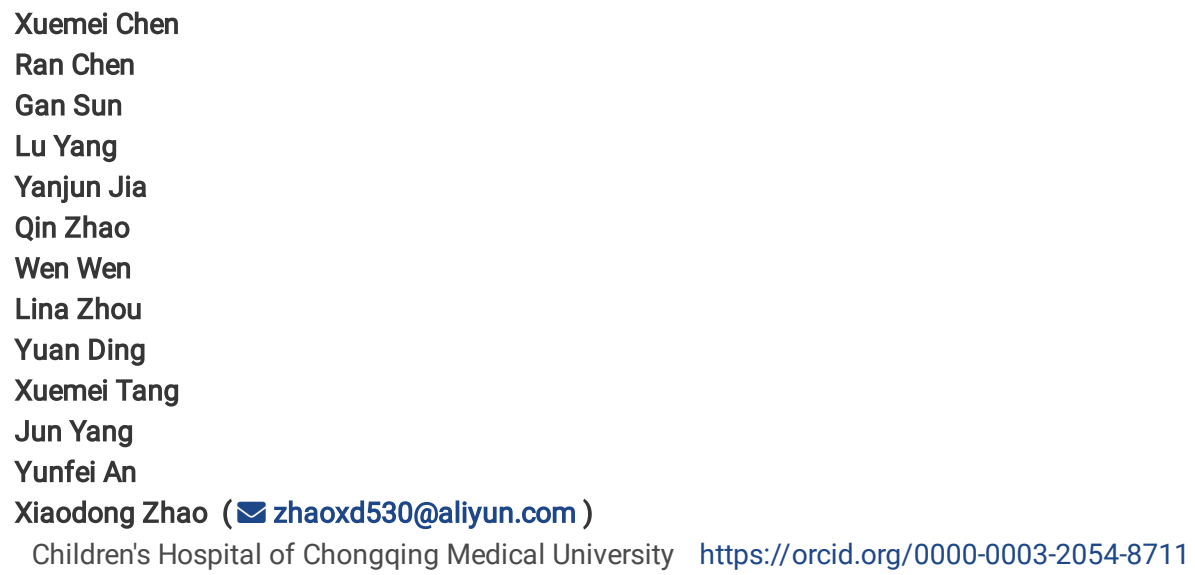

\section{Research Article}

Keywords: STAT1, autosomal dominant, loss-of-function, diverse clinical and immunologic phenotypes

Posted Date: March 7th, 2022

DOI: https://doi.org/10.21203/rs.3.rs-1291912/v1

License: (c) (1) This work is licensed under a Creative Commons Attribution 4.0 International License. Read Full License 


\section{Abstract}

Purpose Mutations in Signal transducer and activator of transcription 1 (STAT1) cause a broad spectrum of disease phenotypes. Heterozygous STAT1 lossof-function (LOF) mutations cause Mendelian susceptibility to mycobacterial diseases (MSMD) and Salmonella infection, both of which are attributable to impaired IFN-y signaling. The identification of novel mutations may extend the phenotypes associated with autosomal dominant (AD) STAT1 deficiency.

Methods Seven patients with heterozygous STAT1 variations were recruited and their clinical and immunologic phenotypes were analyzed, with particular reference to JAK-STAT1 signaling pathways.

Results Five, heterozygous STAT1-deficiency mutations were identified, four of which were novel mutations. Two of the mutations were previously unreported mRNA splicing mutations in AD STAT1 deficient patients. Patients with heterozygous STAT1 deficiency suffered not only mycobacterial infection, but also Candida albicans infection and congenital multiple malformations. AD-LOF mutation impaired IFN-y mediated STAT1 phosphorylation, gamma-activated sequence (GAS) and IFN-stimulated response element (ISRE) transcription activity and IFN-induced gene expression to different extents, which might account for the diverse clinical manifestations observed in these patients.

Conclusion Aberrant splice of STAT1 RNA resulted in AD-LOF for STAT1 signaling. The infectious disease susceptibility and phenotypic spectrum of patients with AD STAT1-LOF are broader than simply MSMD and could overlap with AD STAT1-GOF mutation phenotypes. The susceptibility to infections and immunological deficiency phenotypes, observed in AD-LOF patients, confirms the importance of STAT1 in host-pathogen interaction and immunity. However, variability in the nature and extent of these phenotypes suggests that functional analysis is required to identify accurately novel, heterozygous STAT1 mutations, associated with pathogenicity.

\section{Introduction}

Signal transducer and activator of transcription 1 (STAT1) protein is an important transcription factor and contains a number of distinct N-terminal domains: coiled-coil, DNA-binding, linker, Src homology 2 (SH2), tail segment, and transactivation domains [1]. STAT1 is crucial in interferon-mediated immunity against microbial infections since it regulates the expression of IFN responsive genes [2]. Upon interferon gamma (IFNG) stimulation, STAT1 is phosphorylated on tyrosine 701 (Y701) and form a homodimer, known as gamma-interferon activation factor (GAF). The homodimer is translocated to the nucleus where it binds the gamma-activated sequence (GAS) and induces the transcription of target genes [3,4]. Following interferon alpha (IFNA) stimulation, STAT1 forms a heterotrimer, known as interferon-stimulated gene factor 3 (ISGF3), consisting of STAT1, STAT2, and IRF9. This heterodimer recognizes the IFN-stimulated response element (ISRE) and induces the transcription of target genes [5-7].

Mutations in STAT1 cause a broad spectrum of disease, with distinct mutations being associated with specific, clinical phenotypes. Autosomal recessive (AR) deficiency, complete or partial, results in increased susceptibility to infection by intracellular bacteria and viruses [8-16]. Autosomal dominant (AD) LOF mutation contributes to increased susceptibility to mycobacterial and Salmonella infection, as a result of a defective IFN-y response [1,17-24]. AD gain-of-function mutation is associated with chronic mucocutaneous candidiasis, probably due to impaired Th17 development, which also plays a role in autoimmune disease [25-27].

To date, ten heterozygous STAT1 LOF mutations causing MSMD, through impairment of IFN- $y$ signaling, have been reported. Three of these mutations (p.G250A, p.G250E, p.E157K) are in the coiled-coil domain (CCD) [20,21], two (p.E320Q, p.Q463H) are in the DNA-binding domain (DBD)[1], three (p.K637E, p.M654K, p.K673R) are in the SH2 domain [17,18] and two (p.Y701C, p.L706S) are in the transactivation domain [19, 24]. Until now, heterozygous STAT1 LOF mutations have not been reported as splicing mutations.

In this study, we identified two splicing STAT1 mutations in the DNA-binding domain that are novel mutations in AD STAT1 deficiency. Unlike previously reported cases with STAT1 LOF mutation, one of our patients also presented with Candida albicans infection, three of them suffered from virus infections, and one patient presented with congenital multiple malformations. These findings extend the phenotypes associated with AD STAT1 deficiency.

\section{Materials And Methods}

\section{Patients}

Seven patients from nonconsanguineous families were enrolled in this study. This study was approved by the Medical Ethics Committee of the Children's Hospital of Chongqing Medical University. A written informed consent was obtained from all participants or their parents.

\section{Detection of STAT1 mutations}

Genomic DNA was extracted from peripheral blood lymphocytes by standard procedures using QIAamp DNA Bloodmini kits (Qiagen, Germany). Mutations identified by whole exome sequencing (WES) were confirmed by Sanger sequencing. RNA was extracted from patients by standard procedures using RNA Blood kits (Axygen) and was reverse-transcribed into cDNA using a reverse transcription kit (Takara). The cDNAs from P3 (c.1127+1G>A) and P4 (c.1128$2 A>G$ ) were cloned using TA-cloning and sequenced to determine the splicing error.

\section{Western blotting}


PBMCs were stimulated with IFN-y $\left(2 \times 10^{4} \mathrm{IU} / \mathrm{ml}\right.$; PeproTech) for $0,15,30 / 60,120 \mathrm{~min}$ at $37^{\circ} \mathrm{C}$, then lysed in lysis buffer containing $50 \mathrm{mM} \mathrm{HEPES}, 10 \mathrm{mM}$ $\mathrm{MgCl}_{2}$, and $140 \mathrm{mM} \mathrm{NaCl}(\mathrm{pH}$ 8), supplemented with $0.1 \%$ Tween-20, $1 \% \mathrm{n}$-dodecylbeta-D-maltoside, 2 mM phenylmethylsulfonyl fluoride (PMSF),

proteinase inhibitors, and phosphatase inhibitors (all from Sigma-Aldrich, St. Louis, MO, USA). The lysates were vortexed every $10 \mathrm{~s}$ for 5 min, incubated for $60 \mathrm{~min}$ on ice, and centrifuged at $12000 \times \mathrm{g}$ for $20 \mathrm{~min}$ at $4{ }^{\circ} \mathrm{C}$. Supernatants were diluted $1: 4$ with $5 \times$ loading buffer and heated to $100{ }^{\circ} \mathrm{C}$ for 10 min. Proteins were separated by SDS-PAGE and transferred to nitrocellulose membranes (Bio-Rad, Hercules, CA, USA). The membranes were blocked in $5 \%$ lowfat bovine milk in Tris-buffered saline (TBS) with 0.05\% Tween-20 at room temperature for $1 \mathrm{~h}$. The primary antibodies against phospho-STAT1 (Tyr701) (clone: 58D6, Cell Signaling Technologies, Danvers, MA, USA) and total STAT1 (clone: D1K9Y, Cell Signaling Technologies, Danvers, MA, USA) and that against $\beta$-actin rabbit mAb horseradish peroxidase (HRP)-conjugated (clone: D6A8, Cell Signaling Technologies, Danvers, MA, USA) were used at a 1:1000 dilution. The HRP-conjugated goat anti-rabbit IgG secondary antibody (Cell Signaling Technologies, Danvers, MA, USA) was used at a 1:5000 dilution. Quantitative analysis of Western blot bands was performed using ImageJ (National Institutes of Health, Rockville, MD, USA).

\section{Real-time quantitative PCR}

Total RNA was extracted from whole blood with the Blood Total RNA Miniprep Kit (Axygen). cDNA was transcribed by using Superscript II RT (Invitrogen) and then quantified by TaqMan expression assays with an ABI 7900 sequence detection system (Applied Biosystems). The amplification was performed with denaturation for $15 \mathrm{~min}$ at $94^{\circ} \mathrm{C}$ followed by 40 cycles, $94{ }^{\circ} \mathrm{C}$ for $15 \mathrm{sec}$ and $60^{\circ} \mathrm{C}$ for $1 \mathrm{~min}$. $\beta$-actin was used as a normalization control. The data were analyzed with the $2^{-\Delta \Delta \mathrm{Ct}}$ method and results were expressed as fold induction.

\section{Analysis of TCR-V $\beta$ diversity}

Spectratyping of TCR-V $\beta$ was performed as described previously [28].

\section{Cytokine and cTfh cell measurements}

PBMCs at a density of $2 \times 10^{6} \mathrm{cells} / \mathrm{ml}$ were stimulated with $500 \mathrm{ng} / \mathrm{ml}$ phorbol 12-myristate 13-acetate (PMA) containing $50 \mathrm{ng} / \mathrm{ml}$ ionomycin in the presence of a secretion inhibitor ( $1 \mu \mathrm{l} / \mathrm{ml}$; GolgiPlug; BD Biosciences) for $4 \mathrm{~h}$. PBMCs were washed with PBS and stained with CD3-PerCP (clone: HIT3a, BioLegend) and CD8-BV510 (clone: RPA-T8, BioLegend) for 20 min. Cells were washed twice with PBS, fixed with Fixation and Permeabilization Solution (BD Biosciences) for 30 min at $4{ }^{\circ} \mathrm{C}$, and permeabilized with Perm/Wash Buffer (BD Biosciences) for 20 min at room temperature. Cells were then washed twice with PBS and incubated for 30 min with IL-17A-PE (clone: eBio64CAP17, eBioscience/ThermoFisher Scientific) and IFN-ץ-APC (clone: 4S.B3, BioLegend). Cells were washed twice with PBS and analyzed on a FACSCanto ${ }^{\text {TM }}$ II flow cytometer.

For chemokine receptor staining, to identify circulating follicular helper T cells (cTfh), PBMCs were stained with CD3-PerCP (clone: HIT3a, BioLegend), CD4PE-Cy7 (clone: RPA-T4, BioLegend), CD45RO-APC (clone: UCHL1, BD Biosciences) and CXCR5-BV421 (clone: J25ID4, BioLegend) for 30 min at room temperature. The samples were acquired on a FACSCanto ${ }^{\mathrm{TM}}$ II flow cytometer, and the data were analyzed using Flow Jo.

\section{Luciferase reporter assay}

U3C cells were dispensed into 24-well plates $\left(1 \times 10^{5}\right.$ /well) and transfected, in the presence of polyethylenimine (PEI), with reporter plasmids (GAS and ISRE Reporters) and plasmids carrying one of the mutated alleles of STAT1 or a mock vector. After transfection, for $24 \mathrm{~h}$, cells were transferred back into medium containing $10 \%$ FBS. The transfectants were then stimulated with either IFN- $a$ or IFN- $\gamma$ for $16 \mathrm{~h}$ and subjected to luciferase assays using the Dual Luciferase Reporter Gene Assay Kit (YuanPingHao Bio). Experiments were performed in triplicate and Firefly luciferase activity was normalized with respect to Renilla luciferase activity. Data were expressed as fold induction.

\section{Results}

\section{Clinical manifestations of AD STAT1 deficiency patients}

Kindred A-The subject (P1) was a boy born to nonconsanguineous parents (Fig.1). His mother transmitted the mutation to him but she had no phenotypic characteristics typical of STAT1 deficiency. The uterine sister of P1 died of congenital heart disease. P1 developed recurrent pneumonia and eczema from the age of six months. At the age of 4 years, he developed otitis media and sinusitis. We found Streptococcus pneumoniae and Candida albicans in his nasopharyngeal swab and Aspergillus in his sputum. At the age of 7 years, P1 developed cytomegalovirus (CMV) infection, atrophy of the retina in his right eye and retinal hemorrhage in his left eye. A chest CT scan showed that P1 had double pulmonary bronchiectasis and infection and bilateral axillary lymphadenopathy. Abdominal ultrasound showed his mesenteric lymph nodes were enlarged (Table 1). P1 exhibited decreased CD4 T and serum immunoglobulin (IgA and IgM) levels but his CD56 cell levels were increased (Table 2).

Kindred B - The subject (P2) was a boy born to nonconsanguineous parents (Fig.1). Neither of his parents had ever presented any clinical manifestations that suggested immunodeficiency. At the age of one month, P2 developed BCGosis, which presented as skin erosion around the site of BCG vaccination and enlargement of ipsilateral axillary lymph nodes. A smear of the BCG abscess was positive for acid-fast bacteria. Except for an episode of BCGitis, P2 also had respiratory syncytial virus (RSV) infection. At the age of 5 months, he developed intermittent fever and cough. His chest CT scan showed pneumonia. Abdominal ultrasound showed diffuse enlargement of his liver and spleen (Table 1). At the age of 7 months, a chest CT scan revealed osteomyelitis in his scapula, thoracic vertebra and ribs. At the age of 8 months, X-rays showed multiple bone destruction in the long bones of the extremities (Fig. 3a-P2). His white blood cell, granulocyte and lymphocyte counts were all increased. The percentage of CD3 and CD4 T cells was increased, 
whereas CD19 and CD56 cell counts were decreased. Serum immunoglobulin IgG levels were increased but IgA and IgM levels were within normal ranges (Table 2). P2 underwent abscess incision and drainage at the age of 2 months, after which the left underarm mass subsided significantly. P2 was diagnosed with MSMD and was successfully treated with antimycobacterial agents, including isoniazid and rifampicin, which resulted in a subsequent reduction in bone destruction.

Kindred C - The subject (P3) was a boy born to nonconsanguineous parents (Fig.1). Neither of his parents had any clinical signs suggestive of immunodeficiency. When he was born, P3 was diagnosed with neonatal pneumonia and multiple congenital malformations including esophageal atresia (type IIIA), anal atresia, hypospadias (penis head type), tracheal esophageal fistula, curvature deformity of the right ear, bilateral polycystic kidney with atrophy, bilateral kidney, a hydroureter, and urachal duct fistula. At six months of age, he was diagnosed with congenital heart disease, neuromotor development retardation, and big head deformities. The patient was not vaccinated with BCG and mycobacterium infection was not found (Table 1). No abnormalities were detected by genome-wide CNV analysis, high resolution chromosome, FISH gene, or SRY. The lymphocyte and the serum immunoglobulin levels of P3 were within normal ranges (Table 2). P3 underwent correction of congenital esophageal atresia, colon colostomy, urachal fistula resection, and right auricle deformity correction, and received anti-infection treatment. With continuing treatment, his symptoms gradually improved.

Kindred D - The subject (P4) was a girl born to nonconsanguineous parents (Fig.1). Neither of her parents had ever presented with any clinical manifestations that suggested immunodeficiency. P4 was vaccinated with BCG at the age of one month. After vaccination, she suffered suppuration at the injection site and enlargement of ipsilateral axillary lymph nodes. At five months of age, she developed multifocal osteomyelitis of bilateral tibia, left hand phalanges, and left humerus (Fig. 3a-P4). Histological analysis of her right tibia showed fiber hyperplasia and suppurative inflammation (Fig. 3b-P4). P4 was positive for the PPD skin test, but no pathogenic bacteria, including mycobacteria, were detected by PCR or tissue culture; however, she was found to be suffering from CMV infection. At one year of age, P4 presented with a festering, left big toe nail and increased CD4 T cell levels, but her CD3, CD8, CD19 and CD56 cell counts were normal. IgG, IgA and IgM serum immunoglobulin levels were increased (Table 2), and she was treated with the anti-tuberculous agents isoniazid, rifampicin, ethambutol and levofloxacin, after which her bone destruction decreased significantly.

Kindred E-The subject (P5) was a boy born to nonconsanguineous parents (Fig.1). His father, who transmitted the mutation to him, had a history of spinal tuberculosis before he died of liver cancer. P5 developed BCGosis after BCG vaccination and presented with skin erosion around the site of BCG vaccination and enlargement of ipsilateral axillary lymph nodes (Table 1). At one year of age, he developed posterior process deformity of the lumbar spine and multifocal osteomyelitis of the L1-3 and S1 vertebrae, right fifth rib, right scapula, right femur, right tibia, right frontal top skull, left fibula, left humerus, and left radius (Fig. 3a-P5 ). Histological analysis of bone tissue from the right tibia showed chronic inflammation with granuloma formation (Fig. 3b-P5 I) and chronic inflammation of L1-3 vertebrae tissue (Fig. 3b-P5区). He was positive for both the T-SPOT test and the PPD skin test, but negative for TB-DNA in his bone tissue. The lymphocyte subsets of P5 were normal; however, serum immunoglobulin IgG, IgA, and IgM levels were all increased (Table 2). The patient was treated with the anti-tuberculous drugs isoniazid, rifampicin, ethambutol, and pyrazinamide, after which bone destruction decreased significantly.

\section{Identification of STAT1 mutations}

In this study, we identified five heterozygous STAT1 mutations, four of which were novel mutations, in five kindreds (P1, P3, P4, P5), by WES and Sanger sequencing (Fig.2). Two of the novel mutations were in patients without MSMD. The p.I248T mutation was identified in P1 and his asymptomatic mother. The c.1127+1G >A mutation was identified in P3, who had not been vaccinated with BCG. The other three mutations, p.G250E in P2, c.1128-2A>G in P4, and p.A246T in P5 and the father of P5, were associated with MSMD. Three of the five mutations were missense mutations located in the coiled-coil domain of STAT1 and the other two mutations were splicing mutations located in the DNA-binding domain (Fig.1). For the splicing mutations, the proportion of aberrantly spliced transcripts was determined by sequencing STAT1 cDNA derived from the mRNA of whole blood taken from P3 and P4. This revealed that the $c .1127+1 \mathrm{G}>\mathrm{A}$ mutation (P3) led to splicing out of the whole of exon 13 in $37.5 \%(6 / 16)$ of transcripts and that the $c .1128-2 A>G$ mutation led to splicing out of two amino acids (Phe and Arg) in 36.8\% (7/19) of transcripts (Fig.2).

\section{Multiple osteomyelitis in AD STAT1 deficiency patients}

Three patients developed BCGosis followed by multifocal osteomyelitis after BCG vaccination. The extent of bone destruction in patient P2 included the right scapula, the second and sixth thoracic vertebrae, the bilateral orbital bone, the left temporal bone, and the top of the frontal and long bones of the limbs (Fig.3a-P2). The extent of bone destruction in patient P4 included the left humerus, the left ulnar radius, the fourth metacarpal of the left hand, the proximal phalanx of the left thumb, the right and left tibia fibula, and the phalanges of both feet (Fig.3a-P4). In patient P5 the extent of bone destruction included the frontal bone, the parietal bone, the occipital bone, the lumbosacral 1 vertebral body, the right 5 th rib, the right scapula, the left humerus, the left ulnar radius, the right femur, the right tibia, and the left fibula (Fig.3a-P5).

\section{STAT1 phosphorylation and total STAT1 expression in primary cells from AD STAT1-deficient patients}

p-STAT1 and total STAT1 expression was analyzed by Western blotting of PBMCs from members of five Kindreds stimulated with IFN- $y$ for 0 min, 15 min, 30/60 min, 120 min. P2, P4 and the father of P5 all had normal STAT1 phosphorylation after IFN-y stimulation, but P1, his mother, P3, and P5 all showed impaired STAT1 phosphorylation (Fig.4a, 4b, Table 4). STAT1 expression in the mother of P1, P2, P3, P5, and in the father of P5 was also reduced, compared with healthy controls, but was normal in P1 and P4 (Fig.4c, 4d, Table 4).

Impaired downstream gene induction in response to IFN- $\mathrm{a}$ and IFN-y 
The expression of IFN- $a$ and/or IFN- $y$ inducible genes was investigated by quantitative PCR analysis of PBMCs from four members of the Kindreds stimulated with IFNs (Fig.5). After IFN-a stimulation, MX1 induction was significantly reduced in PBMCs from P4 and P5, whereas GBP1 induction was significantly reduced in PBMCs from P2, P3, P4, P5, and father of P5 (Table 4). For IFN- $\gamma$ inducible genes, the expression of CXCL9 and CXCL10 was significantly reduced in PBMCs from four of the patients. PBMCs from P2 and P4 also showed a significant reduction in IRF1 induction, but the expression of this gene in PBMCs from P3, P5, and father of P5 was comparable to that in PBMCs from healthy controls (Table 4).

\section{Skewed TCR diversity and impaired production of intracellular IL-17A and IFN-Y}

TCR-V $\beta$ diversity was analyzed in five patients (Fig. 6a, 6b). Most of the patients' TCR-V $\beta$ subfamilies exhibited monoclonal or oligoclonal peaks, and TCR repertoire complexity was limited. All the patients exhibited skewed TCR diversity.

Inborn errors of IL-17F and IL-17RA are associated with CMC disease. We also found the proportion of IL-17A and IFN-y-producing T cells was reduced in all patients with STAT1 LOF mutations except for the father of P5 (Fig. 6c, 6e). Similarly, the proportion of cTfh cells was decreased in all patients with STAT1 LOF mutations, with the exception of the father of P5, whose cTfh cell count was comparable to those of healthy controls (Fig. $6 \mathrm{~d}, 6 \mathrm{e}$ )..

\section{STAT1 mutations reduce STAT1 phosphorylation, STAT1 expression, and GAS and ISRE transactivation in vitro}

We transiently introduced WT- and/or mutant-STAT1-containing plasmids into U3C cells, a STAT1-null fibrosarcoma cell line, and analyzed the expression and Y701 phosphorylation of STAT1 after IFN-a or IFN-y stimulation using Western blot analysis (Fig.7a, 7b). Decreased STAT1 phosphorylation and STAT1 expression were observed in cells transfected with each of the mutated (p.I248T, p.G250E, c.1127+1G>A, c.1128-2A>G, p.A246T) alleles (Table 4). By contrast, STAT1 phosphorylation and STAT1 expression increased in cells transfected with an allele containing the $\mathrm{p}$.R274Q mutation, a hotspot GOF mutation in patients with $\mathrm{CMC}$.

The impact of the five STAT1 dominant-negative mutations on the transcriptional activity of GAS and ISRE was analyzed using reporter plasmids (Fig.7c, 7d). There was no significant difference in the transcriptional activity of GAS in cells transfected with either the WT or the p.I248T mutated allele. However, the p.I248T allele reduced the transcriptional activity of ISRE compared with that of the WT allele. The p.G250E, c.1127+1G>A, c.1128-2A>G and p.A246T mutated alleles all reduced the transcriptional activity of both GAS and ISRE relative to that of the WT allele (Table 4).

\section{Discussion}

AD STAT1 deficiency is a rare disease, the hallmark manifestation of which is MSMD. We reviewed a total of 22 cases (11 males and 11 females) with AD STAT1 LOF mutations in previous study (Table 3). All those cases showed clinical manifestation of MSMD and four cases also presented with viral infections. However, none of the cases presented with infection with bacteria, other than mycobacteria, or with fungi. In this study, patients P2, P4, and P5, and the father of P5, showed clinical manifestations of MSMD, while P1 and P3 did not. Three of the patients also presented with viral infections with either CMV (P1 and P4) or RSV (P2). Moreover, two patients presented with non-mycobacterial bacterial infection with Streptococcus (P1) or Klebsiella (P3) and two patients presented with fungal infection with Candida albicans (P1), Aspergillus (P1) or Nocardia farcinica (P5). Since AD STAT1-GOF patients can also present with BCGosis $[27,29]$ and this study showed that AD STAT1-LOF patients can present with fungal infection, it is clear that the clinical infection profile does not categorically differentiate GOF phenotypes from LOF phenotypes. This emphasizes the importance of performing functional analyses on patients or their cells. Surprisingly, P3 presented with multiple organ dysplasia. Using karyotype analysis, WES and CNV, we excluded other chromosomal abnormalities and genetic mutations as the cause of this dysplasia. Thus, it cannot be ruled out that organ dysplasia may be a consequence of more severe STAT1 mutation (Exon skip), mutations in other gene introns, or unidentified environmental factors. Nonetheless, our findings extend the clinical phenotypes associated with AD STAT1 deficiency.

MSMD-causing mutations have been identified in seven autosomal genes (IFNGR1, IFNGR2, STAT1, IL12B, IL12RB1, IRF8, and ISG15) and two X-linked genes (NEMO and CYBB) [30]. In this study three patients with MSMD had BCGitis and multifocal osteomyelitis. In the 22 cases of AD STAT1 deficiency reported previously, BCGitis was observed in $73.3 \%(n=15)$ of patients vaccinated with BCG, $50 \%(n=22)$ of patients with multifocal osteomyelitis, $18 \%$ $(n=22)$ of patients with M. avium infection and $18 \%(n=22)$ of patients with tuberculosis (Table 3). BCGitis and multifocal osteomyelitis, therefore, are the most common clinical manifestations of AD STAT1 deficiency. Since multifocal osteomyelitis was also reported in patients with AD partial IFNYR1 deficiency and AR partial IFNYR1 deficiency [31-36], it may be a characteristic feature of all three of these deficiencies. Thus, the pathogenesis of osteomyelitis appears to be associated with defects in genes (including IFNGR1 and STAT1) involved in the response to IFN- $\gamma$.

Incomplete penetrance of AD STAT1 deficiency has been reported previously and may be the result of epigenetic factors, a lack of exposure to BCG, or even overlooked/undetected clinical manifestations. Interestingly, in this study, the mother of P1 was asymptomatic despite harboring a pathogenic mutation that resulted in functional defects.

Of the five mutation sites in this study, three located in the coiled-coil domain of the STAT1 protein and two located in the DNA-binding domain. Previous studies have shown that the coiled-coil domain plays a key role in protein-protein interactions and mutations in this domain impair both STAT1 dimerization and dephosphorylation of the p-STAT1 protein in the nucleus [37-40]. Mutations in the DNA-binding domain of STAT1 affect its nuclear export and dephosphorylation [41,42]. The ten previously reported heterozygous STAT1 LOF mutations are all missense mutations. In this study, four novel mutations (p.I248T, c.1127+1G>A, c.1128-2A>G, p.A246T) were identified, two of which were splicing mutations. Previously, splicing mutations have been reported in AR STAT1 deficiency but not in AD STAT1 deficiency. Sequencing of cDNA obtained from patients with each of the two splicing mutations 
revealed that aberrantly spliced transcripts accounted for just over one third of STAT1 transcripts, in each case. This may explain why AD-LOF mutation of STAT1 is less deleterious than AR-LOF mutation of STAT1.

We evaluated the effect of the STAT1 mutants in primary cells and STAT1-deficient U3C cells. After stimulation with IFN-y, STAT1 phosphorylation was impaired in primary cells from P1, the mother of P1, P3, and P5. By contrast, STAT1 phosphorylation was normal in primary cells from P2, P4, and the father of P5. In addition, STAT1 protein expression was reduced in primary cells from the mother of P1, P2, P3, P5, and the father of P5, but normal in cells from P1 and P4. Reduced STAT1 phosphorylation and reduced STAT1 expression were observed in U3C cells transfected with each of the five mutant STAT1 alleles compared with cells transfected with WT-STAT1. The transcription activity of GAS and ISRE, in U3C cells expressing either the WT or the individual, mutated STAT1 proteins, was assessed after stimulation with IFN-a or IFN- $y$. GAS transcription activity was impaired in U3C cells transfected with the mutant alleles from P2, P3, P4 and P5, but not P1. ISRE transcription activity was impaired in the presence of all mutant alleles. We also detected the downstream genes expression induced by IFN- $a$ and IFN-y in four patients and P5 father in primary cells, which is contrary to the AD STAT1 GOF mutations [43]. The IFN-a downstream transcription factors MX1, GBP1 and the IFN- $y$ downstream transcription factors CXCL9, CXCL10, IRF1 were decreased significantly. So, it is not always consistent for all the functional analysis. Moreover, primary cell assays are not always consistent with U3C cell line studies in relation to STAT1 phosphorylation and GAS/IRES transcriptional activity. LOF mutations may affect STAT1 phosphorylation, dimerization, transport to nucleus, binding to ISRE/GAS, or even phase separation, which is different to GOF mutations, which are associated with a more consistent, hyper-phosphorylation phenotype. Consequently, more extensive analysis is required to confirm the functional effects of LOF mutations.

The TCR diversity of STAT1 LOF patients was significantly limited. In addition, the levels of IFN-y and IL-17A, produced by the CD $4^{+} \mathrm{T}$ cells of these patients, were also significantly decreased. These features are also characteristic of AD STAT1 GOF mutations [43]. Thus, the above data suggest that AD STAT1 LOF mutations and STAT1 GOF mutations result in overlapping but subtly different pathogenetic mechanisms and clinical phenotypes. For example, the STAT1 GOF patient could suffered MSMD versus the STAT1 LOF patient also suffered fungal infection as P1 and P5 in this study. However, the precise nature of these mechanisms and the elucidation of their differences requires further study.

\section{Conclusion}

In conclusion, we discuss the molecular and phenotypic characterization of seven Chinese patients with AD STAT1 LOF mutations. We found AD STAT1 deficiency not only present MSMD but also present fungal and other bacterial infection. Moreover, we also found that AD STAT1 LOF mutations and STAT1 GOF mutations may have overlapping pathogenetic mechanisms and clinical phenotypes, and further studies are needed.

\section{Declarations}

\section{Acknowledgments}

We thank the patients and their families for their kind cooperation in this study. We thank the members of the laboratory for technical assistance. We thank the doctors and nurses for supporting this project. We also thank Prof. Huawei Mao for providing U3C cells.

\section{Funding}

This work was supported by the Natural Science Foundation of China (Grant Number 81620108014), and the National High Technology Research and Development Program of China (Grant Number 2021YFC2700804).

\section{Competing Interests}

The authors declare that they have no conflicts of interest related to the content of this manuscript.

\section{Author Contributions}

XM.C., YF.A. and XD.Z. designed the study and wrote the manuscript; XM.C., R.C., G.S., L.Y., YJ.J., Q.Z., W.W. did the experiments and analyzed patients' data; XM.C., LN.Z., Y.D., XM.T., J.Y. and YF.A. followed the patients; all authors reviewed the manuscript before publication.

\section{Data Availability}

The data analyzed in the current study is available from the corresponding author on reasonable request.

\section{Ethics approval}

This study was approved by the Medical Ethics Committee of the Children's Hospital of Chongqing Medical University (Approval number:030/2013).

\section{Consent to participate}

Informed consent was obtained from all patients and their parents included in this study.

\section{Consent to publish}

Written informed consent was obtained from all participants included in this study. 


\section{References}

1. Jouanguy E, Vogt G, Feinberg J, Chapgier A, Santos F, Prochnicka-chalufour A, et al. Novel STAT1 Alleles in Otherwise Healthy Patients with Mycobacterial Disease. PLOS Genetics. 2006;2(8):e131.

2. Mckenna A, Hanna M, Banks E, Sivachenko A, Cibulskis K, Kernytsky A, et al. The Genome Analysis Toolkit: A MapReduce framework for analyzing next-generation DNA sequencing data. Genome Res. 2010;1297-303.

3. Vinkemeier U. Getting the message across, STAT1 Design principles of a molecular signaling circuit. Journal of Cell Biology. 2004;167(2):197-201.

4. Chen X, Vinkemeier U, Zhao Y, Jeruzalmi D, Darnell JE, Kuriyan J. Crystal Structure of a Tyrosine Phosphorylated STAT-1 Dimer Bound to DNA. Cell. 1998;93(5):827-39.

5. Pestka S, Krause CD, Walter MR. Interferons, interferon-like cytokines, and their receptors. Immunological Reviews. 2004; $202: 8-32$.

6. Banninger G, Reich NC. STAT2 Nuclear Trafficking. Journal of Biological Chemistry. 2004, 279(38):39199-39206.

7. Bluyssen HAR, Levy DE. Stat2 Is a Transcriptional Activator That Requires Sequence- specific Contacts Provided by Stat1 and p48 for Stable Interaction with DNA. Journal of Biological Chemistry. 1997, 272(7):4600-5.

8. Vairo D, Tassone L, Tabellini G, Tamassia N, Gasperini S, Bazzoni F, et al. Severe impairment of IFN-r and IFN-a responses in cells of a patient with a novel STAT1 splicing mutation. Blood. 2011;118(7):1806-18.

9. Dupuis S, Jouanguy E, Al-hajjar S, Fieschi C, Al-mohsen IZ, Al-jumaah S, et al. Impaired response to interferon- a / $\beta$ and lethal viral disease in human STAT1 deficiency. Nature Genetics. 2003, 33(3):388-391.

10. Chapgier A, Wynn RF, Jouanguy E, Filipe-santos O, Zhang S, Hawkins K, et al. Human Complete Stat-1 Deficiency Is Associated with to Some Low Virulence Viruses In Vivo. Journal of Immunology. 2006;176(8):5078-83.

11. Chapgier A, Kong X, Boisson-dupuis S, Jouanguy E, Averbuch D, Feinberg J, et al. A partial form of recessive STAT1 deficiency in humans. Journal of Clinical Investigation. 2009;119(6):1502-14.

12. Kong X, Ciancanelli M, Al-hajjar S, Alsina L, Zumwalt T, Bustamante J, et al. A novel form of human STAT1 deficiency impairing early but not late responses to interferons. Blood. 2010, 116(26):5895-5906.

13. Kristensen IA, Veirum JE. Novel STAT1 Alleles in a Patient with Impaired Resistance to Mycobacteria. Journal of Clinical Immunology. 2011, 31(2):265271.

14. Sakata S, Tsumura M, Matsubayashi T, Karakawa S, Kimura S, Tamaura M, et al. Autosomal recessive complete STAT1 deficiency caused by compound heterozygous intronic mutations. International Immunology. 2020;32:663-71.

15. Boehmer DFR, Koehler LM, Magg T, Metzger P, Rohlfs M, Ahlfeld J, et al. A novel complete autosomal recessive STAT1 LOF variant causes immunodeficiency with hemophagocytic lymphohistiocytosis-like hyperinflammation. The Journal of Allergy and Clinical Immunology In Practice. 2020;8(9):3102-3111.

16. Rosain J, Nishimura S, Sakura F, Deyà-martinez À, Torun YA, Roynard M, et al. Genetic, Immunological, and Clinical Features of 32 Patients with Autosomal Recessive STAT1 Deficiency. Journal of Immunology. 2021;207(1):133-152.

17. Tsumura M, Okada S, Sakai H, et al. Dominant-negative STAT1 SH2 domain mutations in unrelated patients with Mendelian susceptibility to mycobacterial disease. Human Mutation. 2012, 33(9):1377-1387.

18. Sampaio EP, Bax HI, Hsu AP, Kristosturyan E, Pechacek J, Chandrasekaran P, Paulson ML, Dias DL, Spalding C, Uzel G, Ding L, McFarland E, Holland SM. A novel STAT1 mutation associated with disseminated mycobacterial disease. J Clin Immunol. 2012 Aug;32(4):681-689.

19. Hirata O, Okada S, Tsumura M, Kagawa R, Miki M, Kawaguchi H, et al. Heterozygosity for the Y701C STAT1 mutation in a multiplex kindred with multifocal osteomyelitis. Haematologica. 2013, 98(10):1641-1649.

20. Ueki M, Yamada M, Ito K, Tozawa Y, Morino S, Horikoshi Y, et al. A heterozygous dominant-negative mutation in the coiled-coil domain of STAT1 is the cause of autosomal-dominant Mendelian susceptibility to mycobacterial diseases. Clin Immunol. 2017;174:24-31.

21. Kagawa R , Fujiki R , Tsumura M , et al. Alanine-scanning mutagenesis of human STAT1 to estimate loss- or gain-of-function variants. J Allergy Clin Immunol. 2017; 140(1):232-241.

22. Boudjemaa S, Dainese L, Heritier S, Masserot C, Hachemane S, Casanova JL, Coulomb A. Disseminated Bacillus Calmette-Guerin Osteomyelitis in Twin Sisters Related to STAT1 Gene Deficiency. Pediatr Dev Pathol. 2017;20(3):255-261.

23. Bhattad S, Unni J, Varkey S. MSMD in a 3-Generation Multiplex Kindred Due to Autosomal Dominant STAT1 Deficiency. Journal of Clinical Immunology. 2021;259-61.

24. Dupuis S, Dargemont C, Fieschi C. Impairment of Mycobacterial But Not Viral Immunity by a Germline Human STAT1 Mutation. Science. 2001, 293(5528):300-303.

25. Liu L, Okada S, Kong X-F, Kreins AY, Cypowyj S, Abhyankar A, et al. Gain-of-function human STAT1 mutations impair IL-17 immunity and underlie chronic mucocutaneous candidiasis. J Exp Med. 2011;208:1635-48.

26. Soltész B, Tóth B, Shabashova N, Bondarenko A, Okada S, Cypowyj S, et al. New and recurrent gain-of-function STAT1 mutations in patients with chronic mucocutaneous candidiasis from Eastern and Central Europe. Journal of medical genetics. 2013, 50(9):567-578.

27. Toubiana J, Okada S, Hiller J, Oleastro M, Gomez ML, Becerra JCA, et al. Heterozygous STAT1 gain-of-function mutations underlie an unexpectedly broad clinical phenotype. Blood. 2016;127(25):3154-64. 
28. Langerak AW, Van Den Beemd R, Wolvers-Tettero ILM, Boor PPC, Van Lochem EG, Hooijkaas H, et al. Molecular and flow cytometric analysis of the V $\beta$ repertoire for clonality assessment in mature TCRaß t-cell proliferations. Blood. 2001;98(1):165-73.

29. Zhang W, Chen X, Gao G, Xing S, Zhou L. Clinical Relevance of Gain- and Loss-of-Function Germline Mutations in STAT1: A Systematic Review. Frontiers in Immunology. 2021;12:654406.

30. Pestano J, Vincent QB, Sologuren I, Picard C, Santiago E, Kong X, et al. Partial recessive IFN-gamma R1 deficiency: genetic , immunological and clinical features of 14 patients from 11 kindreds. Hum Mol Genet. 2011;20(8):1509-23.

31. Paz-artal E, Corell A, Allende LM, Lo A, Rez MAGA, Varela P, et al. A Point Mutation in a Domain of Gamma Interferon Receptor 1 Provokes Severe Immunodeficiency. Clinical \& Diagnostic Laboratory Immunology. 2001; 8(1):133-7.

32. Zerbe CS, Holland SM. Disseminated Histoplasmosis in Persons with Interferon-gamma Receptor 1 Deficiency. Clinical Infectious Diseases An Official Publication of the Infectious Diseases Society of America. 2005;41(4):e38-41.

33. Vinh DC, Masannat F, Dzioba RB, Galgiani JN, Holland SM. Refractory Disseminated Coccidioidomycosis and Mycobacteriosis in Interferon-gamma Receptor 1 Deficiency. Clinical Infectious Diseases. 2009;49(6):e62-5.

34. Dorman SE, Picard C, Lammas D, Heyne K, Dissel JT Van, Baretto R, et al. Clinical features of dominant and recessive interferon- $\gamma$ receptor 1 deficiencies. Lancet. 2004;364(9451):2113-2121.

35. Hsu KK, Shea KM, Stevenson AE, Pelton SI. Underlying conditions in children with invasive pneumococcal disease in the conjugate vaccine era. Pediatric Infectious Disease Journal. 2011;30(3):251-70.

36. Lee W, Huang J, Lin T. Chinese Patients with Defective IL-12 / 23-Interferon-y Circuit in Taiwan: Partial Dominant Interferon-y Receptor 1 Mutation Presenting as Cutaneous Granuloma and IL-12 Receptor $\beta 1$ Mutation as Pneumatocele. Journal of Clinical Immunology. 2009, 29(2):238-245.

37. Mertens C, Zhong M, Krishnaraj R, Zou W, Chen X, Jr JED. Dephosphorylation of phosphotyrosine on STAT1 dimers requires extensive spatial reorientation of the monomers facilitated by the N-terminal domain. Genes \& Development. 2006, 20(24):3372-81.

38. Braunstein J, Brutsaert S, Olson R, Schindler C. STATs Dimerize in the Absence of Phosphorylation. Journal of Biological Chemistry. 2003, 278(36):34133-40.

39. Mao X, Ren Z, Parker GN, Sondermann H, Pastorello MA, Wang W, et al. Structural Bases of Unphosphorylated STAT1 Association and Receptor Binding. Molecular Cell. 2005, 17(6):761-771.

40. Mcbride KM, Banninger G, Mcdonald C, Reich NC. Regulated nuclear import of the STAT1 transcription factor by direct binding of importin-alpha. Embo Journal. 2002;21(7):1754-63.

41. Mcbride KM, Mcdonald C, Reich NC. Nuclear export signal located within the DNA-binding domain of the STAT1 transcription factor. Embo Journal. 2000;19(22):6196-6206.

42. Begitt A, Meyer T, Rossum M Van, Vinkemeier U. Nucleocytoplasmic translocation of Stat1 is regulated by a leucine-rich export signal in the coiled-coil domain. Proceedings of the National Academy of Sciences. 2000;97(19):10418-23.

43. Chen X, Xu Q, Li X, Wang L, Yang L, Chen Z, et al. Molecular and Phenotypic Characterization of Nine Patients with STAT1 GOF Mutations in China. Journal of Clinical Immunology. 2020;40(1):82-95.

\section{Tables}

Table 1 Summary of the clinical manifestations of the patients with AD STAT1 LOF mutations

\begin{tabular}{|c|c|c|c|c|c|}
\hline & P1 & P2 & P3 & P4 & P5 \\
\hline Sex & Male & Male & Male & Female & Male \\
\hline Mutation & c. $743 A>G, p .1248 T$ & c.749G>A, p.G250E & c. $1127+1 \mathrm{G}>\mathrm{A}$ (splicing) & $\begin{array}{l}\text { c. } 1128- \\
2 A>G(\text { splicing) }\end{array}$ & $\begin{array}{l}\text { c. } 736 \mathrm{G}>\mathrm{A}, \\
\text { p.A246T }\end{array}$ \\
\hline $\begin{array}{l}\text { BCG } \\
\text { vaccination } \\
\text { status }\end{array}$ & Normal & BCGitis & No $B C G$ vaccine & BCGitis & BCGitis \\
\hline $\begin{array}{l}\text { Infection } \\
\text { episode }\end{array}$ & $\begin{array}{l}\text { Pneumonia, otitis } \\
\text { media, sinusitis }\end{array}$ & $\begin{array}{l}\text { Pneumonia, } \\
\text { multiple } \\
\text { osteomyelitis }\end{array}$ & Pneumonia & $\begin{array}{l}\text { Bronchitis, } \\
\text { paronychia, } \\
\text { multiple } \\
\text { osteomyelitis }\end{array}$ & $\begin{array}{l}\text { Pneumonia, } \\
\text { multiple } \\
\text { osteomyelitis }\end{array}$ \\
\hline Pathogen & $\begin{array}{l}\text { Streptococcus, } \\
\text { Candida albicans, } \\
\text { Aspergillus, CMV }\end{array}$ & $\begin{array}{l}\text { Mycobacterium } \\
\text { tuberculosis, RSV }\end{array}$ & Klebsiella & CMV & $\begin{array}{l}\text { Nocardia } \\
\text { farcinica }\end{array}$ \\
\hline Others & $\begin{array}{l}\text { Recurrent eczema, } \\
\text { bronchiectasis, } \\
\text { retinal atrophy, } \\
\text { lymphadenopathy, } \\
\text { hepatomegaly }\end{array}$ & Hepatosplenomegaly & $\begin{array}{l}\text { Congenital heart disease, Congenital multiple } \\
\text { malformations (esophageal atresia (type IIIA), anal } \\
\text { atresia, hypospadias (penis head type), tracheal } \\
\text { esophageal fistula, curvature deformity of the right } \\
\text { ear, bilateral polycystic kidney with atrophy, } \\
\text { bilateral kidney and hydroureter, urachal duct } \\
\text { fistula), Neuromotor development retardation }\end{array}$ & $\begin{array}{l}\beta \text {-thalassemia, } \\
\text { lymphadenopathy }\end{array}$ & $\begin{array}{l}\text { Spinal } \\
\text { deformity, } \\
\text { anemia }\end{array}$ \\
\hline
\end{tabular}


Table 2. Lymphocyte subpopulations and serum immunoglobulin levels in AD STAT1 LOF patients

\begin{tabular}{|c|c|c|c|c|c|}
\hline & P1 & P2 & P3 & P4 & P5 \\
\hline \multicolumn{6}{|l|}{ White blood cell count } \\
\hline $\operatorname{WBC}\left(10^{\wedge 9} / \mathrm{L}\right)$ & 21.32 & 16.58 & 13.37 & 20.17 & 9.02 \\
\hline Granulocytes $\left(10^{\wedge 9} / \mathrm{L}\right)$ & 14.08 & 8.08 & 7.62 & 9.88 & 4.87 \\
\hline Lymphocytes $\left(10^{\wedge 9} / \mathrm{L}\right)$ & 5.79 & 7.36 & 4.14 & 8.87 & 3.88 \\
\hline Monocytes $\left(10^{\wedge} 9 / \mathrm{L}\right)$ & 0.60 & 0.75 & 0.27 & 0.61 & 0.18 \\
\hline Eosinophils $\left(10^{\wedge} 9 / \mathrm{L}\right)$ & 0.80 & 0.36 & 1.34 & 0.81 & 0.09 \\
\hline \multicolumn{6}{|c|}{ Percentage of lymphocytes } \\
\hline $\mathrm{CD}^{+}$ & 46.1 & 79.3 & 65.3 & 69.9 & 64.11 \\
\hline $\mathrm{CD}^{+} \mathrm{CD}^{+}$ & 11.8 & 58.7 & 46.2 & 53.81 & 29.91 \\
\hline $\mathrm{CD}^{+} \mathrm{CD}^{+}$ & 28.8 & 16.9 & 16.4 & 14.73 & 26.26 \\
\hline $\mathrm{CD}_{19}{ }^{+}$ & 18.6 & 15.3 & 22.6 & 23.21 & 18.05 \\
\hline $\mathrm{CD}_{56^{+}}$ & 33.5 & 4.8 & 10.4 & 6.67 & 17.3 \\
\hline \multicolumn{6}{|c|}{ Immunoglobulins serm levels } \\
\hline $\lg G$ & 5.78 & 26.48 & 10.5 & 17.1 & 18.2 \\
\hline $\lg M$ & 0.441 & 1.46 & 0.28 & 2.25 & 2.37 \\
\hline $\lg A$ & 0.274 & 2.11 & 0.758 & 2.33 & 3.34 \\
\hline
\end{tabular}

Black font, normal; red font, increased; blue font, decreased.

Table 3. Genetic and infectious phenotypes of the international cohort of patients with AD STAT1 deficiency 


\begin{tabular}{|c|c|c|c|c|c|c|c|c|c|c|}
\hline $\begin{array}{l}\text { Patient } \\
\text { [References] }\end{array}$ & Mutation & $\begin{array}{l}\text { Functional } \\
\text { domains }\end{array}$ & Gender & $\begin{array}{l}\text { Age of } \\
\text { onset }\end{array}$ & $\begin{array}{l}\text { Follow } \\
\text { up }\end{array}$ & $\begin{array}{l}\text { BCG } \\
\text { vaccination }\end{array}$ & $\begin{array}{l}\text { Mycobacterial } \\
\text { Disease }\end{array}$ & $\begin{array}{l}\text { Viral } \\
\text { Infections }\end{array}$ & $\begin{array}{l}\text { Other } \\
\text { Bacterial } \\
\text { Infections }\end{array}$ & $\begin{array}{l}\text { Fungal } \\
\text { Infection }\end{array}$ \\
\hline P1[1] & $\begin{array}{l}\text { p. } \\
\text { WT/E320Q }\end{array}$ & DBD & Male & $1 \mathrm{mon}$ & Alive & Yes & BCGitis & $\begin{array}{l}\text { Mumps virus, } \\
\text { VZV, EBV, } \\
\text { measles virus, } \\
\text { rubella virus, } \\
\text { influenza A } \\
\text { virus, } \\
\text { adenovirus, } \\
\text { RSV }\end{array}$ & - & - \\
\hline P2[1] & $\begin{array}{l}\text { p. } \\
\text { WT/Q463H }\end{array}$ & DBD & Male & $2 y$ & Alive & Yes & $\begin{array}{l}\text { M. avium } \\
\text { infection }\end{array}$ & $\begin{array}{l}\text { EBV, RSV, } \\
\text { parainfluenza } \\
\text { virus (I and } \\
\text { III), influenza } \\
\text { virus (A and } \\
\text { B) }\end{array}$ & - & - \\
\hline P3[24] & $\begin{array}{l}\text { p. } \\
\text { WT/L706S }\end{array}$ & TSD & Female & Childhood & Alive & Yes & BCGitis & $\begin{array}{l}\text { HSV-6, EBV, } \\
\text { HPV, VZV, } \\
\text { RSV }\end{array}$ & - & - \\
\hline P4[24] & $\begin{array}{l}\text { p. } \\
\text { WT/L706S }\end{array}$ & TSD & Female & $6 y$ & Alive & No & $\begin{array}{l}\text { M. avium } \\
\text { infection }\end{array}$ & CMV, VZV & - & - \\
\hline P5[17] & $\begin{array}{l}\text { p. } \\
\text { WT/K673R }\end{array}$ & SH2D & Male & Infancy & Alive & Yes & $\begin{array}{l}\text { BCGitis, } \\
\text { multifocal } \\
\text { osteomyelitis }\end{array}$ & - & - & - \\
\hline P6[17] & $\begin{array}{l}\text { p. } \\
\text { WT/K637E }\end{array}$ & $\mathrm{SH} 2 \mathrm{D}$ & Female & 5 mon & Alive & Yes & $\begin{array}{l}\text { BCGitis, } \\
\text { multifocal } \\
\text { osteomyelitis }\end{array}$ & - & - & - \\
\hline P7[18] & $\begin{array}{l}\text { p. } \\
\text { WT/M654K }\end{array}$ & $\mathrm{SH} 2 \mathrm{D}$ & Male & 1week & Alive & No & $\begin{array}{l}\text { M. avium } \\
\text { infection }\end{array}$ & $\begin{array}{l}\text { Typical } \\
\text { childhood } \\
\text { viral } \\
\text { infections } \\
\text { w/o } \\
\text { complications }\end{array}$ & - & - \\
\hline P8[19] & $\begin{array}{l}\text { p. } \\
\text { WT/Y701C }\end{array}$ & TSD & Male & 2 mon & Alive & Yes & $\begin{array}{l}\text { Multifocal } \\
\text { osteomyelitis }\end{array}$ & - & - & - \\
\hline P9[19] & $\begin{array}{l}\text { p. } \\
\text { WT/Y701C }\end{array}$ & TSD & Female & $18 y$ & Alive & Yes & $\begin{array}{l}\text { Multifocal } \\
\text { osteomyelitis }\end{array}$ & - & - & - \\
\hline P10[20] & $\begin{array}{l}\text { p. } \\
\text { WT/G250A }\end{array}$ & CCD & Female & $7 m o n$ & Alive & Yes & $\begin{array}{l}\text { BCGitis, } \\
\text { multifocal } \\
\text { osteomyelitis }\end{array}$ & - & - & - \\
\hline P11[21] & $\begin{array}{l}\text { p. } \\
\text { WT/G250E }\end{array}$ & CCD & Male & $2 y$ & Alive & Yes & $\begin{array}{l}\text { Multifocal } \\
\text { osteomyelitis }\end{array}$ & - & - & - \\
\hline P12[21] & $\begin{array}{l}\text { p. } \\
\text { WT/G250E }\end{array}$ & CCD & Male & $2 y$ & Alive & Yes & $\begin{array}{l}\text { BCGitis, } \\
\text { multifocal } \\
\text { osteomyelitis }\end{array}$ & - & - & - \\
\hline P13[21] & $\begin{array}{l}\text { p. } \\
\text { WT/G250E }\end{array}$ & CCD & Female & - & Alive & Yes & $\begin{array}{l}\text { BCGitis, } \\
\text { multifocal } \\
\text { osteomyelitis }\end{array}$ & - & - & - \\
\hline P14[21] & $\begin{array}{l}\text { p. } \\
\text { WT/G250E }\end{array}$ & CCD & Male & 6 mon & Alive & Yes & $\begin{array}{l}\text { BCGitis, } \\
\text { multifocal } \\
\text { osteomyelitis }\end{array}$ & - & - & - \\
\hline P16[21] & $\begin{array}{l}\text { p. } \\
\text { WT/E157K }\end{array}$ & CCD & Female & 12 mon & Alive & Yes & $\begin{array}{l}\text { BCGitis, M. } \\
\text { avium } \\
\text { infection }\end{array}$ & - & - & - \\
\hline P17[21] & $\begin{array}{l}\text { p. } \\
\text { WT/E157K }\end{array}$ & CCD & Male & Infancy & Alive & - & $\begin{array}{l}\text { Pulmonary } \\
\text { tuberculosis }\end{array}$ & - & - & - \\
\hline P18[21] & $\begin{array}{l}\text { p. } \\
\text { WT/E157K }\end{array}$ & CCD & Female & 9 mon & Alive & Yes & $\begin{array}{l}\text { BCGitis, } \\
\text { multifocal } \\
\text { osteomyelitis }\end{array}$ & - & - & - \\
\hline P19[21] & $\begin{array}{l}\text { p. } \\
\text { WT/E157K }\end{array}$ & CCD & Female & - & Alive & - & Tuberculosis & - & - & - \\
\hline P20[23] & $\begin{array}{l}\text { p. } \\
\text { WT/G250E }\end{array}$ & CCD & Male & - & Alive & Yes & $\begin{array}{l}\text { BCGitis, } \\
\text { multifocal } \\
\text { osteomyelitis }\end{array}$ & - & - & - \\
\hline P21[23] & $\begin{array}{l}\text { p. } \\
\text { WT/G250E }\end{array}$ & CCD & Male & $2.5 y$ & Alive & - & $\begin{array}{l}\text { Spinal } \\
\text { tuberculosis }\end{array}$ & - & - & - \\
\hline
\end{tabular}

Page 10/12 
Table 4. The functional defects caused by AD STAT1 mutations

\begin{tabular}{|c|c|c|c|c|c|c|c|c|c|}
\hline \multirow{2}{*}{$\begin{array}{l}\text { Patient } \\
\text { (Kindred) }\end{array}$} & \multirow[t]{2}{*}{ Mutation } & \multirow[t]{2}{*}{ Deficiency } & \multicolumn{2}{|c|}{ STAT1 Expression } & \multicolumn{2}{|c|}{$\begin{array}{l}\text { STAT1 } \\
\text { Phosphorylation }\end{array}$} & \multirow{2}{*}{$\begin{array}{l}\text { GAS } \\
\text { transcription } \\
\text { activity (U3C } \\
\text { cells) }\end{array}$} & \multirow{2}{*}{$\begin{array}{l}\text { ISRE } \\
\text { transcription } \\
\text { activity (U3C } \\
\text { cells) }\end{array}$} & \multirow{2}{*}{$\begin{array}{l}\text { IFN induced genes } \\
\text { expression (Primary } \\
\text { cells) }\end{array}$} \\
\hline & & & $\begin{array}{l}\text { Primary } \\
\text { cells }\end{array}$ & $\begin{array}{l}\text { U3C } \\
\text { cells }\end{array}$ & $\begin{array}{l}\text { Primary } \\
\text { cells }\end{array}$ & $\begin{array}{l}\text { U3C } \\
\text { cells }\end{array}$ & & & \\
\hline P1 & p.I248T & Partial & Normal & Redused & Redused & Redused & Normal & Redused & NT \\
\hline $\begin{array}{l}\text { P1 } \\
\text { mother }\end{array}$ & p.I248T & Partial & Redused & Redused & Redused & Redused & Normal & Redused & NT \\
\hline P2 & p.G250E & Partial & Redused & Redused & Normal & Redused & Redused & Redused & $\begin{array}{l}\text { GBP1, CXCL9, } \\
\text { CXCL10, IRF1 } \\
\text { redused }\end{array}$ \\
\hline P3 & c. $1127+1 \mathrm{G}>\mathrm{A}$ & Partial & Redused & Redused & Redused & Redused & Redused & Redused & $\begin{array}{l}\text { GBP1, CXCL9, } \\
\text { CXCL10 redused }\end{array}$ \\
\hline P4 & c. $1128-2 A>G$ & Partial & Normal & Redused & Normal & Redused & Redused & Redused & $\begin{array}{l}\text { MX1, GBP1, CXCL9, } \\
\text { CXCL10, IRF1 } \\
\text { redused }\end{array}$ \\
\hline P5 & p.A246T & Partial & Redused & Redused & Redused & Redused & Redused & Redused & $\begin{array}{l}\text { GBP1, CXCL9, } \\
\text { CXCL10 redused }\end{array}$ \\
\hline P5 father & p.A246T & Partial & Redused & Redused & Normal & Redused & Redused & Redused & $\begin{array}{l}\text { MX1, GBP1, CXCL9 } \\
\text { redused }\end{array}$ \\
\hline
\end{tabular}

This table summarizes functional results obtained in cell lines (U3C cells) or primary cells.

GAS, IFN-g activation site; ISRE, IFN-stimulated response element; NT, not tested

\section{Figures}

\section{Figure 1}

Pedigrees and pathogenic STAT1 mutations of the five family. (a) The STAT1 coding region is shown. The regions corresponding to the coiled-coil domain, DNA-binding domain, linker domain, SH2 domain, tail segment domain (TS), and transactivator domain (TA) are indicated, together with their amino acid boundaries. (b) Pedigrees of five kindreds with STAT1 loss-of-function mutations. Each kindred is designated by a letter (A to E), and each generation is designated by a Roman numeral (I-II). Black indicates STAT1 LOF patients, and the probands are indicated by arrows.

\section{Figure 2}

Sequencing of STAT1 mutations. (a) Sanger sequencing results of five patients and their family members. (b) Sequence analysis of cloned STAT1 cDNA from P3 and P4. Exon 13 is deleted in P3 and two amino acids are deleted in P4.

\section{Figure 3}

X-ray examination and biopsy. (a-P2) The density of the long bones of the limbs was uneven, and patchy bone destruction was observed. Periosteum reaction was observed in the left ulna, double femur and tibiofibular (arrow). (a-P4) Patchy low-density shadows were seen in the left tibia, with unclear boundaries and periosteum reaction. The middle and lower segment of the right tibia was swollen and uneven in density, and periosteum reaction was observed (arrow). (a-P5) The middle part of the left fibula was thickened, and patchy bone destruction and periosteum reaction were observed. Bone destruction of L2 and skull. (b-P4囚) Bone tissue of the right tibia: hyperplasia of cancellous interosseous fibrous tissue was observed in the right tibia, local scattered dead bone was observed, numerous neutrophils, lymphocytes, plasma cells and mononuclear macrophages were observed in focal infiltration, 
and local abscess was formed. (b-P4囚) Left axillary lymph node tissue: Structural destruction of lymph nodes with numerous granulomatous structures and multinucleated giant cells. (b-P5区) Bone tissue of the right tibia: chronic inflammation with granuloma formation. (b-P5区) L1-3 chronic inflammation.

\section{Figure 4}

The expression of intracellular p-STAT1 and total STAT1 in the seven study patients. (a) Intracellular p-STAT1 in PBMCs stimulated with IFN- $y$ was detected by Western blotting. (b) The ratio of p-STAT1 to $\beta$-actin was calculated by band densitometry using ImageJ. (c) Total, intracellular STAT1 in PBMCs stimulated with IFN- $\gamma$ was detected by Western blotting. (d) The ratio of total STAT1 to $\beta$-actin was calculated by band densitometry using ImageJ.

\section{Figure 5}

Impairment of downstream gene induction. (a, b) The induction of MX1 and GBP1 were investigated $6 \mathrm{~h}$ after IFN-a stimulation. (c, d, e) The induction of CXCL9, CXCL10 and IRF1 were investigated $6 \mathrm{~h}$ after IFN-y stimulation.

\section{Figure 6}

TCR-V $\beta$ analysis. (a) CDR3 size distribution of TCR-V $\beta$ subfamilies in five STAT1 LOF patients. All 23 TCR-V $\beta$ subfamilies in the healthy controls exhibited a Gaussian distribution. (b) TCR-V $\beta$ complexity scores. The complexity scores for each healthy control (far left) and patient (middle left). The mean (with range) complexity scores of the patient and control groups (middle right). The frequency of TCR-V $\beta$ subfamilies with skewed CDR3 length patterns, as indicated by a complexity score $<4$ (far right). HC, healthy control; P, STAT1 LOF patient; ${ }^{\star} \mathrm{p}<0.05$. (c) Patients had reduced numbers of CD $4^{+} \mathrm{IL}-17 \mathrm{~A}^{+}$and $\mathrm{CD} 4^{+} \mathrm{IFN}-\mathrm{Y}^{+}$cells following stimulation with PMA and ionomycin. (d) Patients had decreased cTfh $\left(\mathrm{CD} 3^{+} \mathrm{CD} 4^{+} \mathrm{CD} 45 \mathrm{RO} \mathrm{CXCR}^{+}\right.$) numbers. (e) Bar chart representation and statistical analysis of the data presented in (c) and (d).

\section{Figure 7}

Functional assays in UC3 cells transfected with WT- or mutated STAT1 alleles. (a) p-STAT1 levels in response to no stimulation (NS), IFN-a, or IFN- $\gamma$ stimulation. (b) Total STAT1 levels in response to no stimulation (NS), IFN-a, or IFN- $\gamma$ stimulation. (c) GAS activation after IFN-y stimulation. (d) ISRE activation after IFN-a stimulation. 